\author{
RESEARCH ARTICLE \\ 10.1029/2019JC015701 \\ Key Points: \\ - Ocean color and mooring data show \\ similar variability at interannual, \\ seasonal, and intraseasonal time \\ scale in the NW Mediterranean Sea \\ - In the NW spring bloom region, \\ intraseasonal SChl fluctuations \\ explain $50 \%$ of variance and occur at \\ spatial scales of synoptic wind bursts \\ - In oligotrophic regions, \\ intraseasonal SChl fluctuations \\ explain $10-20 \%$ of variance and \\ occur at spatial scales of oceanic \\ mesoscale activity
}

Supporting Information:

- Figure S1. Supporting Information

Correspondence to:

M. G. Keerthi,

keerthanaamg@gmail.com

Citation:

Keerthi, M. G., Levy, M., Aumont, O., Lengaigne, M., \& Antoine, D. (2020). Contrasted contribution of

intraseasonal time scales to surface chlorophyll variations in a bloom and an oligotrophic regime. Journal of Geophysical Research: Oceans, 125, e2019JC015701. https://doi.org/ 10.1029/2019JC015701

Received 26 SEP 2019 Accepted 20 APR 2020 Accepted article online 26 APR 2020

(C)2020. American Geophysical Union. All Rights Reserved.

\section{Contrasted Contribution of Intraseasonal Time Scales to Surface Chlorophyll Variations in a Bloom and an Oligotrophic Regime}

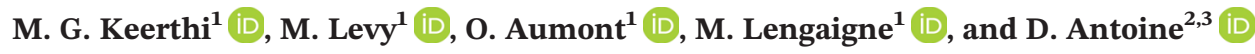 \\ ${ }^{1}$ Sorbonne Université (CNRS/IRD/MNHN), LOCEAN-IPSL, Paris, France, ${ }^{2}$ Remote Sensing and Satellite Research \\ Group, School of Earth and Planetary Sciences, Curtin University, Perth, Western Australia, ${ }^{3}$ Laboratoire \\ d'Océanographie de Villefranche, LOV, Sorbonne Université, CNRS, Villefranche-sur-Mer, France
}

Abstract Understanding long-term variations of ocean ecosystems requires untangling the time scales involved in their natural fluctuations. We applied a temporal decomposition procedure to two decades of satellite ocean color observations to characterize the time variability of surface chlorophyll-a (SChl) in the Mediterranean Sea. In order to assess the reliability of the satellite data at capturing intraseasonal, seasonal, and interannual variability, we first show that satellite SChl data compare well with field data of chlorophyll-a fluorescence from the long-term BOUSSOLE time series, at all three time scales. The decomposition procedure is then applied to satellite SChl and to mixing-layer depth (MxLD) data from an ocean reanalysis, both at the scale of the entire Mediterranean Sea. Our results reveal similar amplitude for the seasonal and intraseasonal SChl variations in the northwestern bloom region, together explaining about $90 \%$ of the SChl variance. Coherent seasonal SChl variations occur at the scale of the bloom region $(\sim 400 \mathrm{~km})$ and are tightly connected with seasonal MxLD changes. Intraseasonal SChl fluctuations occur at smaller spatial scales ( 100 km), suggesting they would be generated by storms although they weakly correlate to variations of the MxLD reanalysis. Over the oligotrophic part of the Mediterranean Sea, about $80 \%$ of the variability in both SChl and MxLD are explained by basin-scale $(\sim 1,000 \mathrm{~km})$ seasonal variations. Intraseasonal variability occurs at much smaller spatial scales, typical of mesoscale activity $(\sim 30 \mathrm{~km})$. These results support the hypothesis that seasonal SChl variations are driven by changes in MxLD, while mesoscale activity and storms drive the intraseasonal SChl fluctuations.

Plain Language Summary In the context of our changing climate, an ongoing challenge is to be able to reliably detect and attribute trends in ocean color records of surface chlorophyll-a (SChl), which is the only observable variable representative of the state of marine ecosystem available at global scale. However, the magnitude of the natural variability of SChl is much stronger than that of the SChl long-term trend. Furthermore, this natural variability occurs over a large range of unrelated time scales, making it difficult to detect and attribute a climate-driven trend. Here we focus on the variability over temporal scales that have been overlooked because their observation requires continuous measurements, that is, fluctuations that are shorter than seasonal ones. In the case of the Mediterranean Sea, we show that such intraseasonal variations can be as large as seasonal ones and that they may also be less predictable because they likely ensue from processes such as storms or ocean eddies.

\section{Introduction}

In recent decades, anthropogenic climate change has impacted ocean ecosystems and thus human communities in various ways (Bindoff et al., 2019). An ongoing challenge is to be able to reliably detect and attribute long-term trends in ocean color records of surface chlorophyll-a (SChl), the only observable variable representative of the state of marine ecosystem available at the global scale. Even though more than two decades of satellite SChl over the world ocean are now available, the confidence in appraising SChl trends is still low (Bindoff et al., 2019). One of the reasons is that SChl fluctuations are characterized by large natural variability over a wide range of temporal scales, and a better understanding of this large natural variability is necessary to confidently attribute a climate change trend (Henson et al., 2010; Henson et al., 2016).

Typically, SChl low-frequency (i.e., interannual) variations and long-term trends emerge after filtering seasonal and intraseasonal fluctuations. This is often simply achieved by computing trends from annually 
Climatological SChl

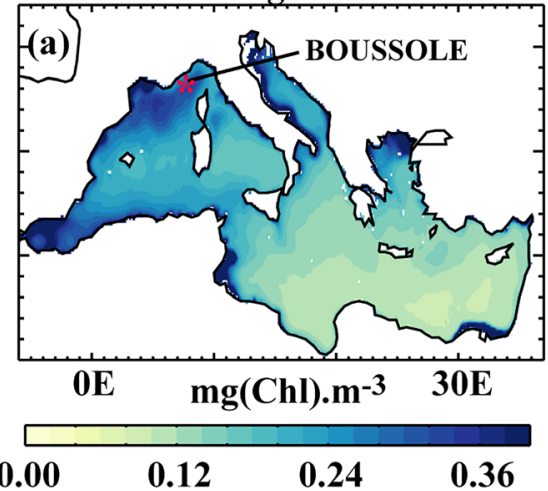

Coefficient of variance of SChl

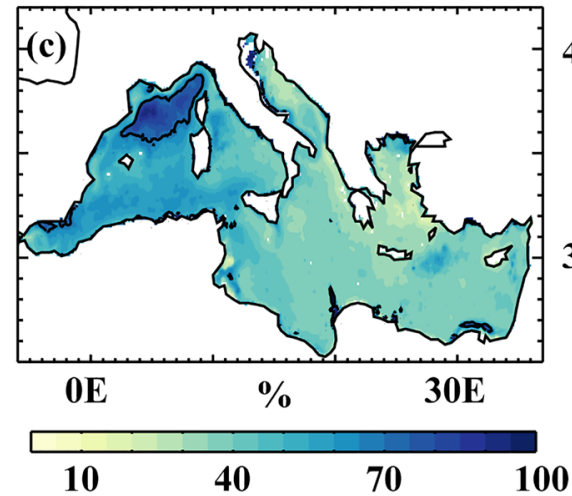

Climatological winter MxLD

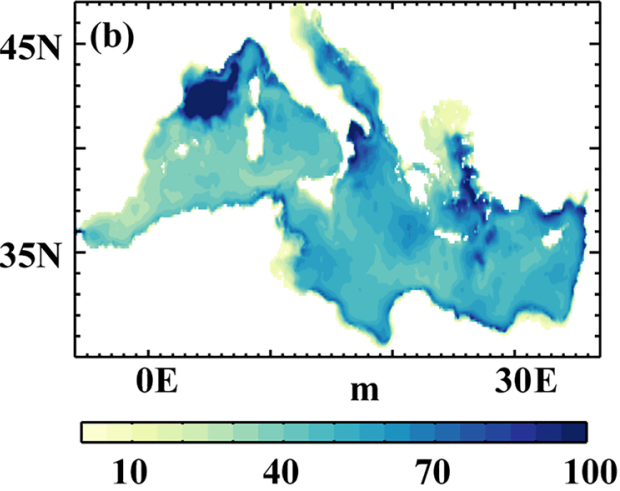

Data coverage of SChl

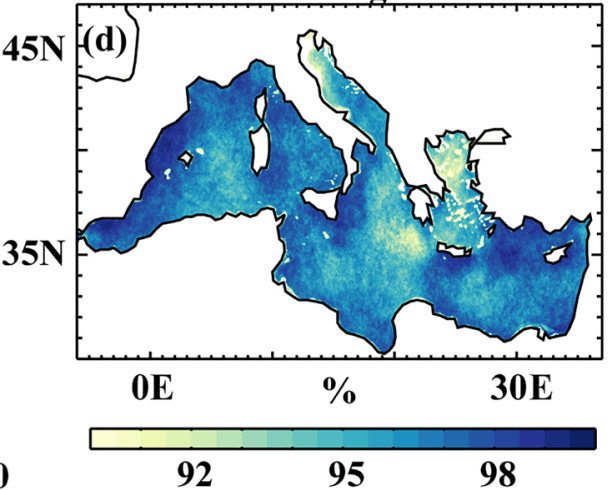

Figure 1. (a) Annual mean surface chlorophyll (SChl) distribution over the period 1998-2017, using ESA OC-CCI SChl, (b) mean winter (Dec-Jan-Feb) mixing-layer depth (MxLD) over the period 1998-2012, using MxLD data from the Mercator reanalysis MEDRYS1V2, (c) normalized SChl variance (standard deviation divided by the mean of SChl), and (d) ESA OC-CCI SChl data coverage (percentage of time steps with data in each pixel with respect to the total number of time steps). The BOUSSOLE mooring location is marked by a star in panel (a). The $70 \%$ contour is highlighted in panel (c).

averaged SChl data (Behrenfeld et al., 2006; Chavez et al., 2011; Gregg \& Rousseaux, 2014; Martinez et al., 2009). This simple strategy may be suitable to filter out seasonal fluctuations but not intraseasonal fluctuations, which are less predictable and whose variance may be close to or even larger than the seasonal one (Salgado-Hernanz et al., 2019; Thomalla et al., 2011). Spring phytoplankton blooms which are typical SChl seasonal fluctuations at middle and high latitudes in the open ocean are, for example, often characterized by a succession of rapid SChl increases and decreases and hence exhibit a strong intraseasonal component (Mayot et al., 2017; Salgado-Hernanz et al., 2019; Taylor \& Ferrari, 2011). This implies that year-to-year variations of the bloom project over a wide range of time scales. Understanding low-frequency and long-term variations of the bloom hence requires a proper assessment of its interannual, seasonal, and intraseasonal variations.

Overall, and despite their potential importance, intraseasonal SChl fluctuations have received much less attention than their seasonal or interannual counterparts. The focus of this work is to contribute to filling this gap by providing a quantitative characterization of intraseasonal SChl variability in the ocean, evaluating its contribution to total variability and its spatial scales as well as suggesting plausible driving mechanisms. This is a prerequisite toward a better understanding of the drivers of low-frequency (i.e., interannual up to multidecadal) variability and long-term trends.

A difficulty when quantifying intraseasonal SChl variations from satellite ocean color observations arises from the presence of clouds, which mask satellite retrieval over time scales similar to the ones we aim at capturing. To avoid this caveat, the present study investigates the temporal variability of SChl in the Mediterranean Sea, where cloud cover is generally low (Figure 1d). Moreover, we take advantage of the 
presence of a fixed mooring at an offshore site in the bloom region of the northwestern Mediterranean Sea, which provides high-frequency, multiyear in situ fluorescence data (Figure 1a, BOUSSOLE site, Antoine et al., 2006, 2008). The BOUSSOLE time series is unique in length and temporal resolution and is used to assess the reliability of merged satellite products in capturing intraseasonal SChl variability. The Mediterranean Sea also offers the advantage of hosting contrasted production regimes, including a spring bloom regime typical of other oceanic regions such as the North Atlantic (Bernardello et al., 2012; d'Ortenzio et al., 2014; d'Ortenzio \& Ribera d'Alcalà, 2009; Houpert et al., 2015; Houpert et al., 2016; Lavigne et al., 2013; Lévy et al., 1999; Mayot et al., 2016; Migon et al., 2020; Ruiz et al., 2019; Volpe et al., 2012). In order to quantify intraseasonal SChl variations, we extract the intraseasonal, seasonal, and interannual signals from the ocean color SChl time series using a method adapted from Vantrepotte and Mélin (2011). With this method, the three signals are distinguished by their time scale of variability, typically above 1 year for interannual, between 6 months and 1 year for seasonal, and below 6 months for intraseasonal.

Intraseasonal SChl variations may ensue from processes acting over a wide range of spatial scales. They can be driven by intraseasonal basin-scale climate modes such as the Madden-Julian oscillation (Resplandy et al., 2009), by synoptic atmospheric forcing resulting from storms (Carranza \& Gille, 2015; Fauchereau et al., 2011) and tropical cyclones (Menkès et al., 2016), or by oceanic mesoscale and submesoscale processes (Lévy et al., 2018; Mahadevan et al., 2012; Pascual et al., 2017; Ruiz et al., 2019) acting at even smaller scales. In the open Mediterranean basin, we expect storms and eddies to be the main driving mechanisms. Attributing in a quantitative way, the drivers of intraseasonal SChl variations is challenging, because it requires the knowledge of these drivers at high temporal resolution. Here we have attempted to compare $\mathrm{SChl}$ intraseasonal variations with variations in mixing-layer depth (hereafter MxLD) data issued from an ocean reanalysis, and we show the limit of this comparison. We propose an indirect approach, which consists in quantifying the spatial scales associated with intraseasonal fluctuations. The underlying rationale is that intraseasonal SChl variations driven by storms are likely to occur over larger spatial scales than those driven by oceanic mesoscale and submesoscale processes.

The paper is organized as follows. Section 2 briefly reviews the regional context. Section 3 describes the data products and the statistical methods used to extract the intraseasonal signals and compute the spatial scales of variability, and section 4 presents the main results. The paper ends with a discussion of these results in section 5 .

\section{Regional Context}

The Mediterranean Sea is predominantly an oligotrophic basin, with a strong east-west trophic gradient (Figure 1a). Two dominant trophic regimes coexist characterized by their specific seasonal evolution of phytoplankton, often referred to as "bloom" and "no-bloom" regimes (Bosc et al., 2004; de Fommervault et al., 2015; d'Ortenzio \& Ribera d'Alcalà, 2009; Lavigne et al., 2013; Mayot et al., 2016, 2017; Nieblas et al., 2014).

The most productive northwestern "bloom" regime (hereafter NW bloom) exhibits a typical temperate pattern (d'Ortenzio et al., 2014; Mitchell \& Holm-Hansen, 1991; Sverdrup, 1953) characterized by an increase in SChl that starts in fall, often interrupted in winter, and a stronger more intense bloom in spring that ends in summer (Bricaud et al., 2002; d'Ortenzio et al., 2014; Houpert et al., 2015; Houpert et al., 2016; Mayot et al., 2016). This region exhibits the highest SChl variance ( $>70 \%$, Figure 1c). It is the location of deep convection in winter that leads to a deepening of the mixing layer (Figure 1b). This deep mixing efficiently refuels the surface layer with nutrients. The spring SChl peak is driven by the seasonal stratification of the mixing layer, implying a time lag between this SChl peak and the maximum depth reached by vertical mixing (d'Ortenzio et al., 2005; Houpert et al., 2015; Houpert et al., 2016; Lavigne et al., 2013; Lazzari et al., 2012; Levy et al., 1998; Marty \& Chiavérini, 2010).

The remaining of the basin hosts a "no-bloom" regime, a typical low-productivity subtropical regime (Figure 1a), with smaller seasonal SChl variations (Figure 1c). In this regime, the winter mixing layer is much shallower ( $<70 \mathrm{~m}$, Figure 1c), and SChl peaks when the mixing layer is the deepest (Lavigne et al., 2013), nutrients being used as soon as they are injected into the euphotic layer. 
Numerous processes such as mesoscale and submesoscale activity, frontal dynamics, coastal influences, and interannual to long-term variability modulate the productivity in this basin (d'Ortenzio et al., 2014; d'Ortenzio \& Ribera d'Alcalà, 2009; Estrada, 1996; Houpert et al., 2015; Houpert et al., 2016; Lavigne et al., 2013; Lévy et al., 1999; Mayot et al., 2016; Ruiz et al., 2019). As a consequence, time series of SChl exhibits clear year-to-year variations in the timing, amplitude, and spatial extent of the spring bloom in the NW bloom regime (Bernardello et al., 2012; Estrada, 1996; Mayot et al., 2016; Volpe et al., 2012).

\section{Data and Methods}

\subsection{Satellite SChl}

We based our study on the data processed by the European Space Agency Ocean Color Climate Change Initiative (ESA OC-CCI; Sathyendranath \& Krasemann, 2014; Sathyendranath et al., 2017). More precisely, we used the Level-3 Standard Mapped Images at $4 \times 4 \mathrm{~km}$ spatial and 8 day temporal resolutions from January 1998 to December 2017 (available at http://www.oceancolour.org/). This product merges data from the Moderate Resolution Imaging Spectroradiometer (MODIS)-Aqua, the Sea-Viewing Wide Field-of-View Sensor (SeaWiFS), and the MEdium Resolution Imaging Spectrometer (MERIS). The correlation between OC-CCI SChl and matching in situ chlorophyll is 0.66 (Volpe et al., 2007). This correlation is not improved when using regionally tuned algorithms such as MedOC4-CCI, although OC-CCI slightly overestimates low SChl values compared to MedOC4-CCI (Volpe et al., 2007). Nevertheless, for practical reasons, we chose the standard OC-CCI product because the regional MedOC4-CCI product is only available at time and space resolution finer than the one needed here. This choice is further discussed in section 5.

The data coverage of OC-CCI SChl is greater than $90 \%$ over the Mediterranean Sea (Figure 1d). Grid cells with less than $90 \%$ of data were discarded, and the remaining temporal gaps in the time series were filled by linear interpolation. These data are further regridded to a spatial resolution of $1 / 8^{\circ}(\sim 13-14 \mathrm{~km})$ to reduce the computational demand of the analysis.

\subsection{BOUSSOLE Fluorescence}

We made use of in situ fluorescence measurements at $9 \mathrm{~m}$ depth from the BOUSSOLE mooring located in the Ligurian Sea at $7^{\circ} 54^{\prime} \mathrm{E}, 43^{\circ} 22^{\prime} \mathrm{N}$ (Antoine et al., 2006) to evaluate the performance of the satellite data at capturing SChl variability in the NW bloom region. The original fluorescence data has a 15 min temporal resolution and was available from 2007 to 2017 at the time of this study. Eight-day composites were constructed from the original data to allow a fair comparison with the satellite data. It must be noted that the few gaps arising from technical issues in the data acquisition (particularly in 2008 and 2010) may partly bias the 8 day composites during these periods.

In order to avoid contamination of the fluorescence signal by quenching, we only considered night data. To compare the in situ and satellite data sets, we converted the fluorescence signal into SChl using a constant multiplicative coefficient. This coefficient (2.4) was determined by fitting the fluorescence data to the satellite matchups following the methodology developed by Lavigne et al. (2012) and satisfactorily applied to convert fluorescence data to chlorophyll concentration in the Mediterranean Sea (Lavigne et al., 2015). The chlorophyll satellite data were averaged over a $1^{\circ}$ box around the mooring location, before being used in the fitting procedure of fluorescence data.

In order to apply the temporal decomposition procedure to the in situ BOUSSOLE time series, the missing data in the 8 day field, which represent $17 \%$ of the original BOUSSOLE time series, were interpolated linearly or filled using the satellite SChl data around the mooring, when available. For a fair comparison with the satellite SChl product and temporal decomposition, they were subsequently masked in all the analyses discussed in this study.

\subsection{Model Reanalysis MxLD}

We also used the MxLD product from the Mercator reanalysis MEDRYS1V2 (Hamon et al., 2016). The MEDRYS ocean reanalysis is based on a $1 / 12^{\circ}(\sim 7 \mathrm{~km})$ horizontal resolution and 75 vertical level model configuration of the Mediterranean Sea with the NEMO ocean model, NEMO MED12. This eddy-permitting resolution enables to simulate an elevated level of eddy activity, especially in the Alboran and Ionian regions (Hamon et al., 2016). The atmospheric forcing used in MEDRYS is ALDERA—the dynamical downscaling 


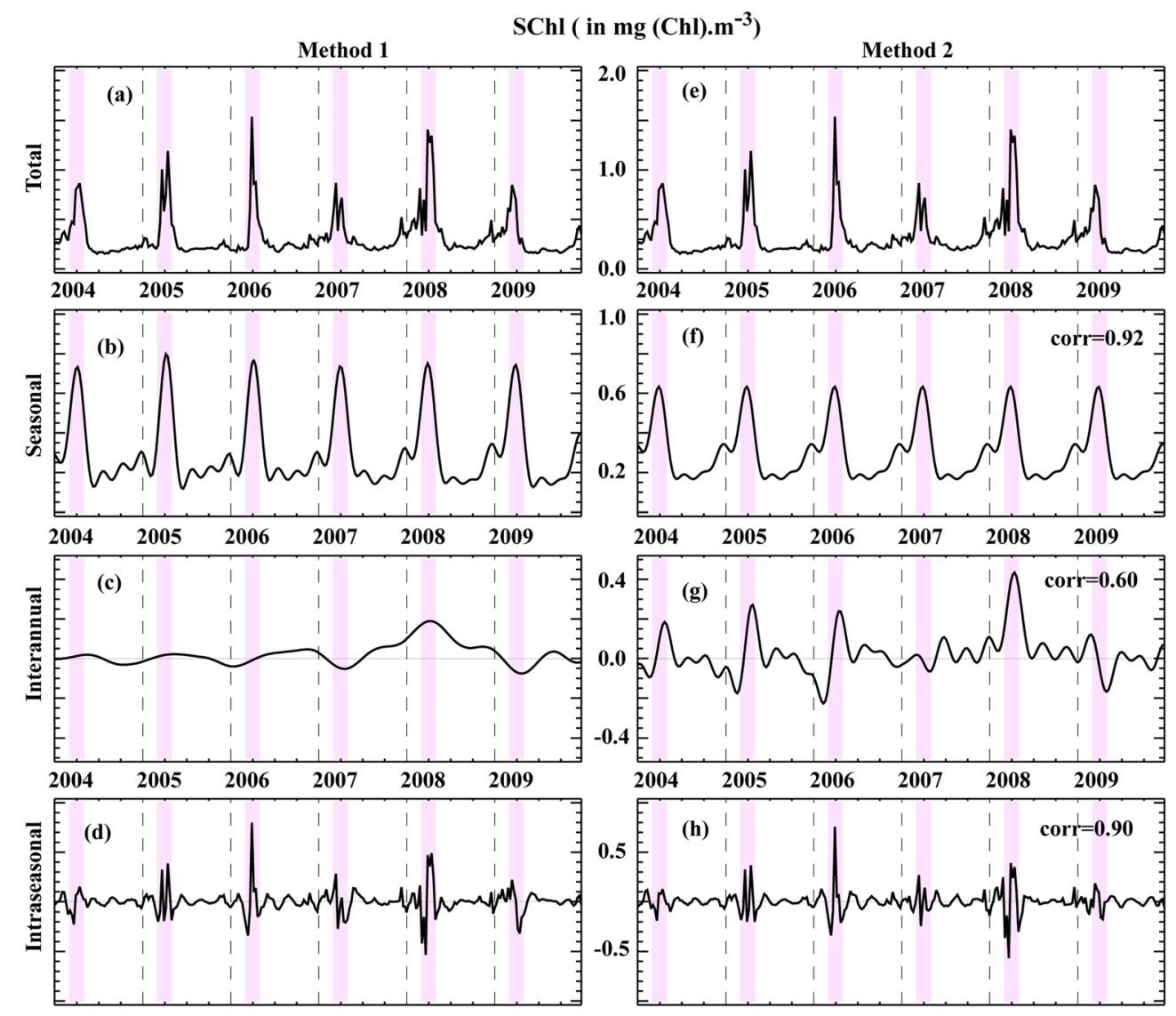

Figure 2. Decomposition of the ESA OC-CCI SChl time series at the $1^{\circ} \times 1^{\circ}$ BOUSSOLE mooring box (a, e) into seasonal $(\mathrm{b}, \mathrm{f})$, interannual (c, g), and intraseasonal ( $\mathrm{d}, \mathrm{h})$ components. Method 1 (left panels) is used in this paper and is characterized by a seasonal cycle that is allowed to vary from year to year. Method 2 (right panels) is shown for comparison and uses a seasonally repeating seasonal cycle. For clarity, only the period from 2004 to 2009 is shown (the full time series shown in supporting information Figure S2). Correlations between the two methods are indicated on the right panels and are for the full time series (1998 to 2017). The pink shading highlights the March-April period, which is when the peak of the spring bloom occurs.

of the ERA-Interim atmospheric reanalysis implemented with the regional climate model ALADIN-Climate. MEDRYS uses the Mercator Ocean data assimilation system SAM2 (Brasseur et al., 2005). Altimeter data, satellite SST, temperature, and salinity vertical profiles are jointly assimilated.

We defined the MxLD as the turbocline depth, that is, the depth of the water column over which the vertical diffusivity coefficient is larger than $5 \times 10^{-4} \mathrm{~m}^{2} \mathrm{~s}^{-1}$. The daily, $1 / 12^{\circ} \mathrm{MxLD}$ data available over the periodextending from January 1998 to December 2012 were regridded to 8 day composites on the same grid $\left(1 / 8^{\circ}\right)$ as the OC-CCI SChl regridded product.

The MEDRYS reanalysis is shown to perform better than hindcast simulations in terms of average temperature and salinity (Hamon et al., 2016). However, its performance in capturing the MxLD, or even the mixed-layer depth (MLD, i.e., the layer defined by a density difference of 0.01 with surface density), is difficult to assess because of the lack of data, particularly at the spatial and temporal scales necessary for this study (i.e., intraseasonal and down to the mesoscale).

\subsection{Time Scale Decomposition}

A SChl time series $X_{t}$ can be decomposed into seasonal $\left(S_{t}\right)$, interannual $\left(T_{t}\right)$, and intraseasonal $\left(I_{t}\right)$ components, such that $X_{t}=S_{t}+T_{t}+I_{t}$. A variety of approaches have been used in the past to perform such decomposition. For instance, Thomalla et al. (2011) have compared the full SChl time series to a repeated, mean seasonal cycle computed at each location to study the variability of phytoplankton blooms in the 
Southern Ocean. Alternatively, Vantrepotte and Mélin (2011) and Salgado-Hernanz et al. (2019) have incorporated year-to-year variations in the seasonal signal and have accounted for these variations before extracting the interannual signal. The SChl time series at the BOUSSOLE site reveals strong variations at seasonal time scale (Figure 2a and supporting information Figure S1a). To account for these variations, we used a method adapted from Vantrepotte and Melin (2011) in which the seasonal cycle is allowed to vary from year to year (Method 1, left panels in Figure 2). We discuss the sensitivity to this choice by repeating the analysis using a second method in which the seasonal cycle is strictly periodic (Method 2, right panels in Figure 2). Unless specified, all analysis presented in the core of this paper make use of the first decomposition method.

Method 1, with year-to-year variations in the seasonal cycle: The decomposition is based on a simplified version of the statistical method initially developed in the X11 software by the U.S. Bureau of the Census, commonly referred to as the Census X-11 algorithm (e.g., Vantrepotte \& Mélin, 2009). Census $\mathrm{X}-11$ is an iterative algorithm, which uses simple moving averages, Henderson filters and band pass filters to decompose a timeseries $X_{t}$ into $S_{t}, T_{t}$, and $I_{t}$. Previous studies (e.g., Colella et al., 2016; Vantrepotte \& Mélin, 2009, 2011) have applied the Census X-11 decomposition procedure to monthly data sets, with the aim of investigating the seasonal and interannual variations of ocean biogeochemical parameters. We adapted this procedure to data with a higher temporal resolution (8 day composites) to extract intraseasonal variations. The decomposition is applied at the level of individual grid cells and requires continuous time series with no data gap. This modified algorithm consists of eight successive steps, which are described below.

(a) Initial estimate.

(1) Estimation of the first interannual component $\left(\mathrm{T}_{\mathrm{t}}{ }^{1}\right)$ by an annually centered moving average (47 terms moving average as each year contains 46 time steps) on the initial time series $X_{t}$. $Z_{t}$, defined as $\mathrm{Z}_{\mathrm{t}}=\mathrm{X}_{\mathrm{t}}-\mathrm{T}_{\mathrm{t}}^{1}$, comprises the seasonal and intraseasonal components.

(2) Estimation of the first seasonal component $\left(S_{t}{ }^{1}\right)$, by applying a seasonal running mean on $Z_{t}$. First, $Z_{t}$ is averaged over three successive years at every time step of the considered years: $\mathrm{S}_{\mathrm{t}}{ }^{0}=\left(\mathrm{Z}_{\mathrm{t}(\mathrm{i}-1, \mathrm{~m})}+2\left(\mathrm{Z}_{\mathrm{t}}\right.\right.$, , $m)+Z_{t}(i+1, m) / 4$, where $Z_{t}(i, m)$ is the series subsample for each time step $m=1,2, . .46$ of each year $i=1,2 \ldots \mathrm{n}$. The resulting time series $\left(\mathrm{S}_{\mathrm{t}}{ }^{0}\right)$ is then normalized by subtracting its annually centered running mean $\left(\mathrm{MS}_{\mathrm{t}}{ }^{0}\right) \cdot \mathrm{S}_{\mathrm{t}}{ }^{1}=\mathrm{S}_{\mathrm{t}}{ }^{0}-\mathrm{MS}_{\mathrm{t}}{ }^{0}$. The seasonally adjusted series is then computed as $\mathrm{Z}_{\mathrm{t}}{ }^{1}=\mathrm{X}_{\mathrm{t}}-\mathrm{S}_{\mathrm{t}}{ }^{1}$.

(b) Revised estimate.

(3) The improved estimate of the interannual component $\left(\mathrm{T}_{\mathrm{t}}^{2}\right)$ is obtained by applying a Henderson filter (Henderson, 1916) of weight 51 on the seasonally adjusted series $\left(\mathrm{Z}_{\mathrm{t}}{ }^{1}\right)$. Then the interannual adjusted series is estimated, $\mathrm{Z}_{\mathrm{t}}^{2}=\mathrm{X}_{\mathrm{t}}-\mathrm{T}_{\mathrm{t}}^{2}$.

(4) Step (2) is applied on the interannual adjusted series $\left(Z_{t}^{2}\right)$ to obtain the secondary estimate of the seasonal component $\left(S_{t}^{2}\right)$. Then the seasonally adjusted series is estimated, $Z_{t}^{3}=X_{t}-S_{t}^{2}$.

(5) The intraseasonal signal $\left(\mathrm{I}_{\mathrm{t}}{ }^{1}\right)$ is estimated by applying a bandpass filter of 8-88 days on the secondary estimate of the seasonal component $\left(\mathrm{S}_{\mathrm{t}}{ }^{2}\right)$. We should note that we also tested a five-step running mean on $\mathrm{S}_{\mathrm{t}}^{2}$ instead of the bandpass filter. Both approaches gave similar variability at intraseasonal and seasonal time scales, and we opted for the bandpass filter.

(c) Final estimate.

(6) The interannual component $\left(\mathrm{T}_{\mathrm{t}}\right)$ is estimated by repeating step (3) to the seasonally adjusted series $\left(\mathrm{Z}_{\mathrm{t}}{ }^{3}\right)$.

(7) The seasonal component $\left(\mathrm{S}_{\mathrm{t}}\right)$ is obtained by subtracting $\left(\mathrm{I}_{\mathrm{t}}{ }^{1}\right)$ from $\left(\mathrm{S}_{\mathrm{t}}{ }^{2}\right)$.

(8) The intraseasonal component $\left(\mathrm{I}_{t}\right)$ is the sum of the components $\left(\mathrm{I}_{t}{ }^{1}\right)$ and $\left(\mathrm{X}_{t}-\mathrm{S}_{\mathrm{t}}-\mathrm{T}_{t}\right)$.

The seasonal cycle $\left(\mathrm{S}_{\mathrm{t}}\right)$ is defined locally and allows variations in amplitude from year to year, which helps to diagnose the stability of the seasonal cycle (Vantrepotte and Melin, 2009). The interannual component $\left(T_{t}\right)$ captures variability with periodicity greater than 8 months, while the intraseasonal component captures variability with periodicity between 8 (the temporal resolution of the data set) and 90 days and all the irregular variability beyond periodicities of 90 days. We should note that the long-term trend was not removed before decomposition and is thus part of the interannual component.

Method 2, with a repeated mean seasonal signal: This method is adapted from Keerthi et al. (2016, 2017). In this approach, the seasonal signal is computed as the sum of the first four harmonics, and the coefficients of the four harmonics are computed for each grid cell with a least squares fit to the full time series. 

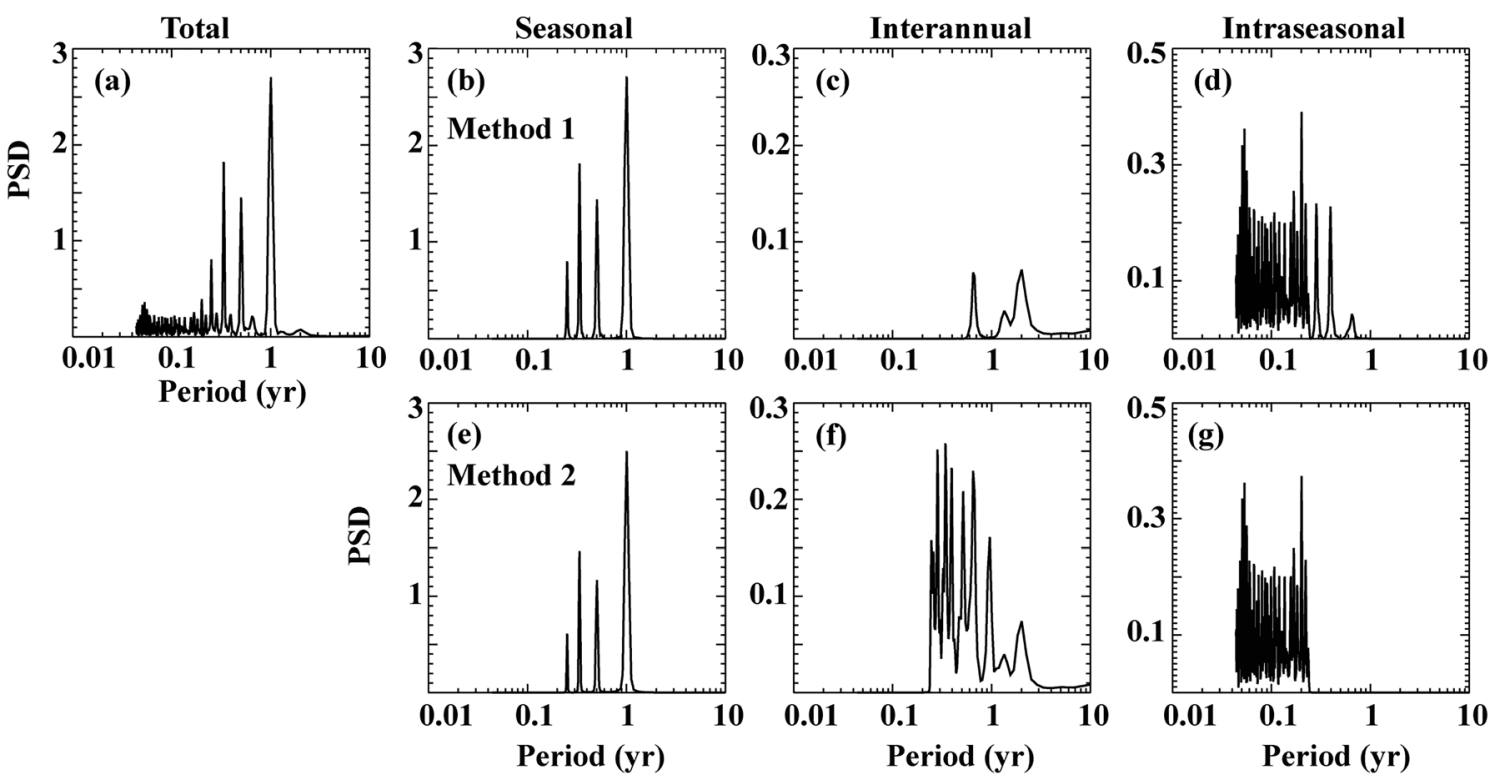

Figure 3. Power Spectrum of the (a) total, (b, e) seasonal, (c, f) interannual, and (d, g) intraseasonal ESA OC-CCI SChl time series at the $1^{\circ} \times 1^{\circ}$ BOUSSOLE mooring box from 1998-2017 obtained with a decomposition method characterized by a seasonal cycle that is allowed to vary from year to year (Method 1, b, c, d, used in this paper) and with another method shown for comparison (Method 2, e, f, g, that uses a seasonally repeating seasonal cycle). The time series corresponding to these power spectra are shown in Figure 2 and supporting information Figure S1.

Intraseasonal signals are then isolated using an 8 to 88 day bandpass filtering based on Fourier transform. Interannual anomalies are then calculated by removing the seasonal and intraseasonal signals.

As an illustration, Figure 2 shows the decomposition of the ocean color SChl time series at the BOUSSOLE site into its seasonal, interannual, and intraseasonal components by the two methods. By construction, the largest differences between the two decomposition methods appear in the interannual component because it contains interannual variations of the seasonal cycle in the second method but not in the first. In addition, the Fourier spectrum of the signals produced by the two decomposition methods (Figure 3) nicely illustrates that the first method separates better than the second the frequencies of interannual fluctuations from those of the seasonal and intraseasonal signals. Importantly, the intraseasonal signals obtained with the two methods are very similar with a correlation of 0.9 , which shows that the extraction of this signal marginally depends on the choice made to extract the interannual signal. The main difference between the two intraseasonal signals concerns periodicities larger than 90 days, which have been filtered out by construction in the second method but remain in the first method.

\subsection{Total Variance Partitioning}

The total variance var $\left(X_{t}\right)$ of the original time series can be written as $\operatorname{var}\left(X_{t}\right)=\operatorname{var}\left(S_{t}\right)+\operatorname{var}\left(I_{t}\right)+\operatorname{var}$ $\left(T_{t}\right)+2 \operatorname{cov}\left(S_{t}, I_{t}, T_{t}\right)$, where $\operatorname{var}\left(S_{t}\right)$, var $\left(I_{t}\right)$ and $\operatorname{var}\left(T_{t}\right)$ represent the variances associated with the seasonal, intraseasonal, and interannual components, respectively. $\operatorname{Cov}\left(S_{t}, I_{t}, T_{t}\right)$ is the covariance of the seasonal, intraseasonal, and interannual components. This term makes up only a few percent of the total variance and is not discussed further in the rest of the study. The relative contribution of each component to the total signal is expressed as a percentage.

\subsection{Spatial Scales of SChl Variability}

To quantify the spatial extension of the patterns of variability for each time scale, the decomposed time series at a given grid cell is cross correlated with the corresponding time series at all other grid cells in the basin. This provides a cross-correlation map for each time scale and each grid cell. We then computed the number of grid cells for which the cross-correlation is larger than a threshold value of 0.8 and the area that they cover. This threshold is to some extent arbitrary, but our results are weakly sensitive for values ranging from 0.75 to 0.85 (supporting information Figure S4). We define the spatial scale of variability for that particular time scale, threshold, and grid cell, as the square root of this area expressed in $\mathrm{km}$. This space scale should be 

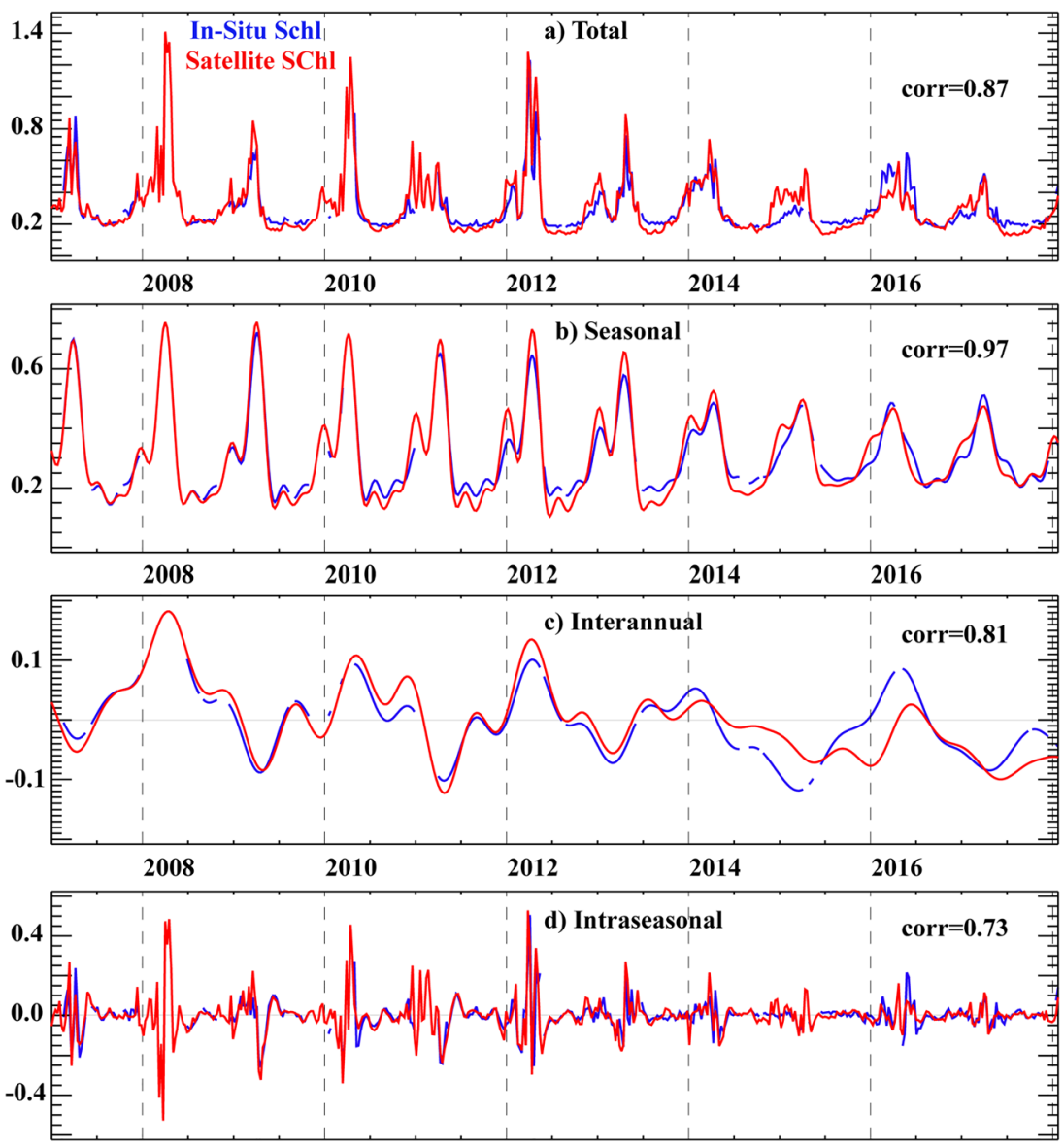

Figure 4. Comparison of the ESA OC-CCI (red curves) SChl time series (a) and its decomposition into seasonal (b), interannual (c), and intraseasonal (d) components with in situ data at the BOUSSOLE mooring (blue curves). Gaps in the in situ data are due to instrumental problems. Correlation between the in situ and satellite SChl components are given in each panel. Note that different scales on the $y$ axis are used for the total, seasonal, interannual, and intraseasonal signals.

viewed as the distance over which the intraseasonal (respectively, the seasonal or interannual) signal remains self-coherent (in the limit of the chosen cross-correlation threshold value).

\subsection{Influence of Intraseasonal SChl Variability at Large Spatial Scale}

To evaluate the large-scale imprint of intraseasonal variance, the gridded intraseasonal time series were filtered in space to retain only the spatial scales larger than a given threshold. We varied the threshold between 50 and $500 \mathrm{~km}$. We adopted the method in Keerthi et al. (2013, 2016), an iterative application of the heat diffusion equation described in Weaver and Courtier (2001). This analysis allowed us to evaluate how much of the intraseasonal variance was still present at scales above $50 \mathrm{~km}$ and how fast it decreased between 50 and $500 \mathrm{~km}$.

\section{Results}

In order to evaluate the ability of the satellite product to capture intraseasonal SChl variations, we first present the temporal scale separation at a single station located in the NW bloom region (the BOUSSOLE mooring) where high-frequency in situ data are also available over the 2007-2017 period. We then extend the analysis over the entire basin and a longer time period (1998-2017) and evaluate the corresponding spatial scales, using the satellite product alone. Finally, we attempt to contextualize these results by repeating the same analysis to the MxLD derived from an oceanic reanalysis. 

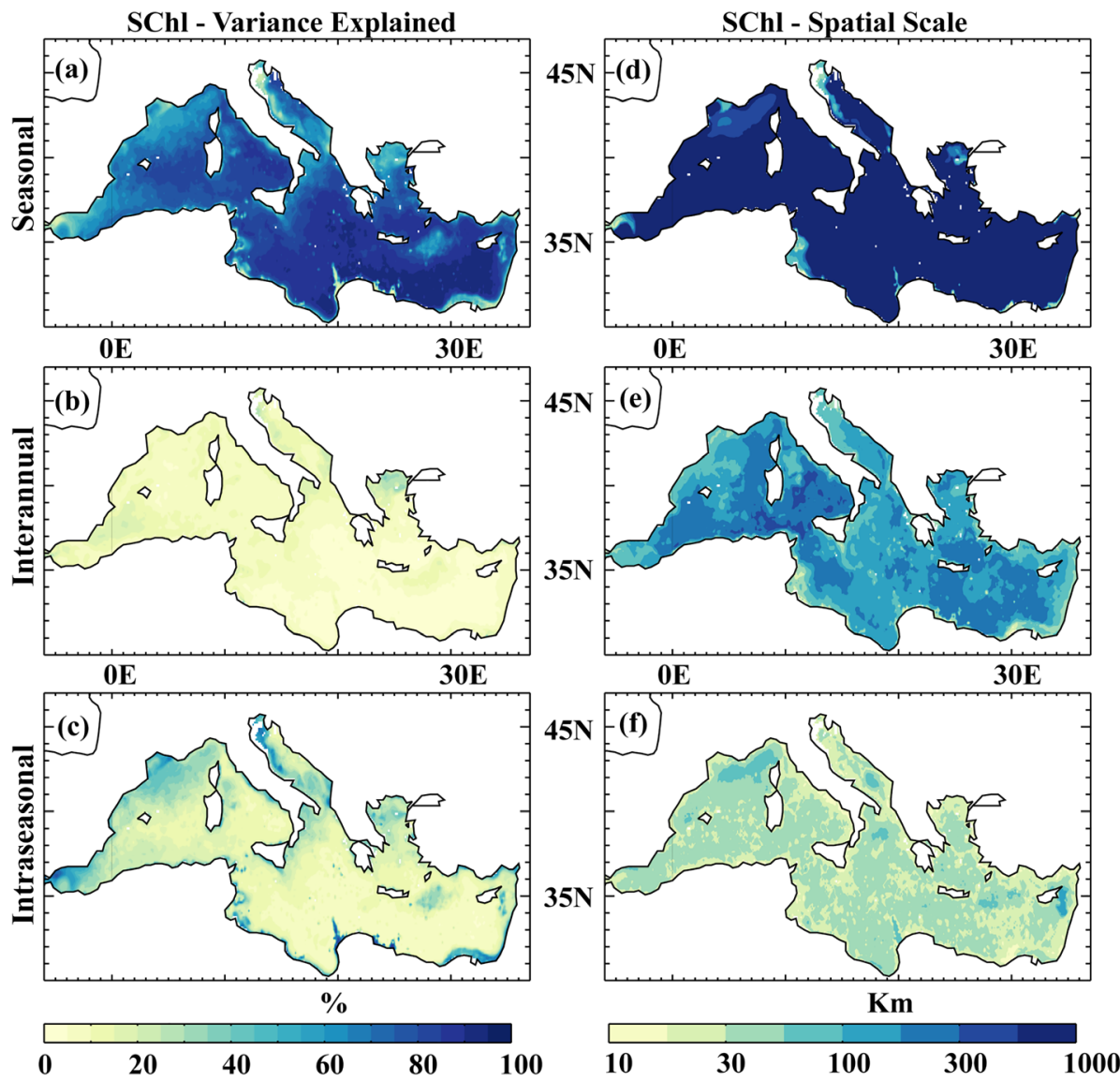

Figure 5. (first column) Percentage of the total SChl variance explained by its (a) seasonal, (b) interannual, and (c) intraseasonal components. (second column) Spatial scales associated to (d) seasonal, (e) interannual, and (f) intraseasonal SChl components.

\subsection{Characterizing and Comparing Satellite and In Situ SChl Variability at the BOUSSOLE Mooring}

The BOUSSOLE mooring is located at the northwestern end of the NW bloom regime (star in Figure 1a). The blue curve in Figure 4a displays the in situ BOUSSOLE time series over the 2007-2017 period. As reported before (Lavigne et al., 2013; Mayot et al., 2016; Salgado-Hernanz et al., 2019), the in situ SChl time series exhibits an intense bloom in spring (between March and April), with strong year-to-year variations in amplitude and peak timing. This time series also shows a clear decreasing linear trend of $\sim-0.01 \mathrm{mg} \mathrm{m}^{-3} \mathrm{yr}^{-1}$ over this time period, in line with a previous estimate by Salgado-Hernanz et al. (2019) performed over 1998-2014 and based on the MedOC4-CCI product. At the BOUSSOLE mooring, seasonal variations explain $\sim 60-70 \%$ of the total SChl variance, the remaining being explained by intraseasonal ( 20-30\%) and interannual ( 5$10 \%$ ) variations.

The associated seasonal component (blue curve in Figure 4b) is typical of the bloom regime, with a strong peak in spring followed by low and stable SChl concentrations in summer. A second more modest peak occurs in fall, which is then interrupted in winter. The amplitude and phenology of this seasonal SChl signal also display significant year-to-year modulations. In addition to a decreasing trend in the spring peak amplitude, the secondary peak in fall evident prior to 2015 is not detected after that year. At interannual time scales (blue curve, Figure 4c), the variability is characterized by alternating periods of positive and negative anomalies of modest amplitude. At intraseasonal time scales (blue curve, Figure 4d), the signal is relatively large and shows a wide spectrum of periods, ranging from a couple of weeks to several months (Figure 3d). Intraseasonal fluctuations generally exhibit their largest variations during the spring bloom and during years with a strong bloom. 
Figure 4 also allows comparing in situ SChl time evolution (blue curve) with satellite retrieved concentrations (red curve) over their overlapping time period. The total signals of the two time series agree generally well in terms of phasing and year-to-year variations in the peak amplitude, with an overall correlation of 0.87, significant at $90 \%$ (Figure 4a). This agreement between the two data sources occurs at all time scales (Figures $4 \mathrm{~b}-4 \mathrm{~d})$, although it is larger at seasonal $(r \sim 0.97)$ than at interannual $(r \sim 0.8)$ and intraseasonal $(r \sim 0.73)$ time scales. The comparatively poorer agreement at intraseasonal time scales is however expected because the 8 day composites of both time series are biased by different time distributions of missing data. This could also ensue from the constant coefficient used to compare in situ fluorescence to satellite SChl. The overall good agreement between the two independent data sets however gives us confidence that the satellite product reliably captures the time evolution of SChl down to the intraseasonal time scales at the BOUSSOLE station, and allows us to confidently use the merged satellite SChl to investigate SChl variability at seasonal, interannual, and intraseasonal time scales in the Mediterranean Sea, where the data coverage is close to that of BOUSSOLE (Figure 1d).

\subsection{Spatio-Temporal Characterization of Intraseasonal SChl Variations at the Scale of the Basin}

The relative contribution of intraseasonal fluctuations to the total SChl variance is compared to the contribution of seasonal and interannual fluctuations (Figures $5 \mathrm{a}-5 \mathrm{c}$ ). As expected, seasonal variations contribute the most to the total variability, with a contribution ranging from $50 \%$ in the northwestern part to $90 \%$ in the southeastern part. The second contributor to the total variance is the intraseasonal component, with a contribution ranging from $10 \%$ in the interior of the basin to $50 \%$ near the shore, in the NW region, in the Rhodes Gyre and in the western Alboran Sea. Finally, interannual variations are the smallest contributor to the total variance (from less than $10 \%$ to $20 \%$ ). An important result for the present study is that the SChl variance in the core of the NW bloom region is explained almost equally by seasonal ( 45\%) and intraseasonal ( 45\%) variations, with interannual variability accounting for the remaining $10 \%$. In contrast, over most oligotrophic regions, the weaker SChl variance is explained mainly by seasonal variations. An exception is the Rhodes Gyre where the seasonal cycle explains $~ 50 \%$ of the total signal, while the intraseasonal and interannual variations equally contribute to the remaining $50 \%$. Along the western Alboran Sea, near to the Gibraltar strait, where the climatological SChl values are large (Figure 1a), intraseasonal variability explains around $60-70 \%$ of the total SChl variance, while the seasonal cycle explains only $20-30 \%$ of it.

The spatial scales of intraseasonal SChl variations are further compared to those of seasonal and interannual variations (Figures 5d-5f). These spatial scales represent the distance over which the signal at a given time scale remains self-coherent and reflect the spatial scale of the mechanisms driving these intraseasonal variations. Broadly speaking, there is a general decrease of the spatial scales associated with seasonal (>400 km), interannual ( 100-400 km) and intraseasonal $(\sim 20-100 \mathrm{~km})$ variability. This is consistent with the fact that seasonality in SChl is a wide regional phenomenon, while more local processes drive intraseasonal fluctuations. Also interestingly, the scale of interannual variability is smaller than that of seasonal variability, which is not something we anticipated.

The spatial scales associated with seasonal variations (Figure $5 \mathrm{~d}$ ) exceed 1,000 km over most of the Mediterranean Sea, that is, they have a scale close to the scale of the basin (1,760 km wide by 4,510 km long). A notable exception is the NW bloom region where the seasonal spatial scale $(\sim 400 \mathrm{~km})$ is close to the scale of the bloom region itself ( $550 \mathrm{~km}$ wide by $880 \mathrm{~km}$ long). This clear separation is consistent with the previous identifications of the "bloom" and "no-bloom" bioregions based on the SChl phenology (de Fommervault et al., 2015; d'Ortenzio \& Ribera d'Alcalà, 2009; Lavigne et al., 2013; Mayot et al., 2016).

At intraseasonal time scales (Figure $5 f$ and supporting information Figure $S 4$ ), the spatial scales are wider in the NW bloom region $(\sim 100 \pm 40 \mathrm{~km})$ than in the rest of the basin $(\sim 30 \pm 10 \mathrm{~km})$. The Mediterranean Sea is prone to intense mesoscale activity (Fernández et al., 2005), with a rather small Rossby radius ( 10 km) and intense mesoscale eddies with a 20-30 km radius (Escudier et al., 2016; Pinardi \& Masetti, 2000). The spatial scales of the intraseasonal variability in the oligotrophic part of the basin $(\sim 30 \mathrm{~km})$ are consistent with the hypothesis that the nutrient supply induced by mesoscale dynamics may reach the surface and sustain intraseasonal SChl variability there (i.e., de Fommervault et al., 2015; Lévy et al., 2012; Lévy et al., 2018; McGillicuddy, 2016). 

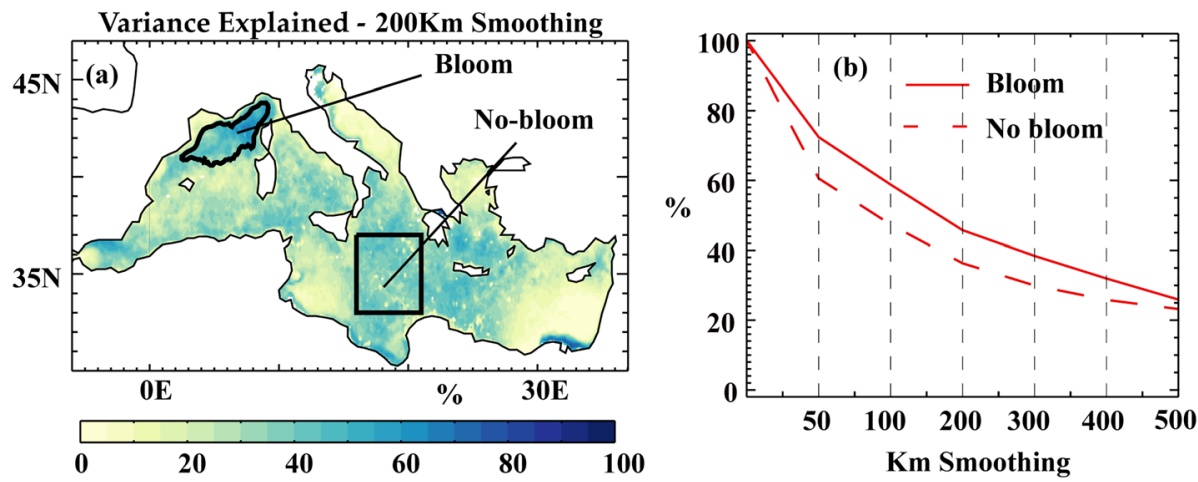

Figure 6. (a) Percentage of the intraseasonal SChl variance that remains after applying a $200 \mathrm{~km}$ smoothing filter to the intraseasonal signal. (b) Percentage of the intraseasonal SChl variance that remains after applying a spatial smoothing filter of varying scale to the intraseasonal signal, averaged over the bloom region (thick curve) and the no-bloom region (dashed curve). The nonsmoothed data are represented as the $0 \mathrm{~km}$ smoothing. The bloom no-bloom regions are indicated in panel a.

In the bloom region, however, the scales are too large to be related to mesoscale processes alone. They are closer to the scale of the synoptic atmospheric variability related to Mistral and Tramontane winds that frequently blow over the region (Bernadallo et al., 2012; Marra et al., 2019; Gaertner et al., 2016). These cold and dry winds are associated with large sensible and latent heat fluxes and occur as strong storms that last for a few days (Mertens \& Schott, 1998; Leaman \& Schott, 1991; Bernadallo et al., 2012). They enhance surface cooling over this region and generate cold patches of roughly $100 \mathrm{~km}$, that is, about the spatial scales of intraseasonal SChl variability (Madec et al., 1996; Marshall \& Schott, 1999). Such intense wind bursts and the associated cooling erode the near surface stratification, leading to deeper vertical mixing which limits phytoplankton growth but also resupplies the surface with nutrients (Leaman \& Schott, 1991; Mertens \& Schott, 1998). Thus, spatial scale analysis suggests that intraseasonal variability of SChl could be driven by these wind bursts over the bloom region.

At interannual time scales (Figure 5e), the spatial scales are more homogeneous and do not show any clear regional pattern. The $100-400 \mathrm{~km}$ scale range suggests a relationship to the scales of the mean circulation and hydrology (Bosse et al., 2015; Pascual et al., 2007; Robinson et al., 2001; Testor et al., 2005). In the Mediterranean Sea, the general circulation is structured in subbasin-scale gyres of diameter 200-350 km (Robinson et al., 2001), driven by the wind and heat fluxes forcing, and locked by the topography (d'Ortenzio \& Prieur, 2012; Molcard et al., 2002; Pinardi et al., 1997). Interannual variations in the structure and intensity of the wind forcing drive important interannual variations in the surface circulation (Demirov \& Pinardi, 2002; Molcard et al., 2002; Pinardi et al., 1997), which has an impact on surface water characteristics, and consequently drives interannual anomalies in SChl (Olita et al., 2011; Volpe et al., 2012).

To quantify the influence of intraseasonal variations over larger spatial scales, Figure 6 estimates how much of the intraseasonal variance remains for scales larger than a given threshold, over the range 50-500 km. This analysis shows the decrease in total intraseasonal variance at increasing scale of influence. Both in the bloom and no-bloom regions, there is, as expected, a sharp decrease over the first $200 \mathrm{~km}$ (Figure 6b). Nevertheless, over large regions, more than $40 \%$ of the variance is retained after filtering the intraseasonal signal at $200 \mathrm{~km}$ (Figure 6a).

\subsection{Relationship With the Mixing-Layer Depth Variability}

In the Mediterranean Sea, seasonal variations in SChl are known to be driven by seasonal variations in MxLD, both in the bloom region and in the more oligotrophic regions (Levy et al., 1998; D'Ortenzio et al., 2005; Marty \& Chiavérini, 2010; Lazzari et al., 2012; Lavigne et al., 2013; Houpert et al., 2015, 2016). Thus to contextualize the SChl analysis, we compared the variability in SChl with the variability in MxLD at the three time scales. Our intention was to infer whether or not the link between SChl and MxLD at seasonal time scale holds for the other time scales, and to what extent they may explain intraseasonal fluctuations. The limit of this approach is that the best available MxLD product is derived from a model reanalysis, 

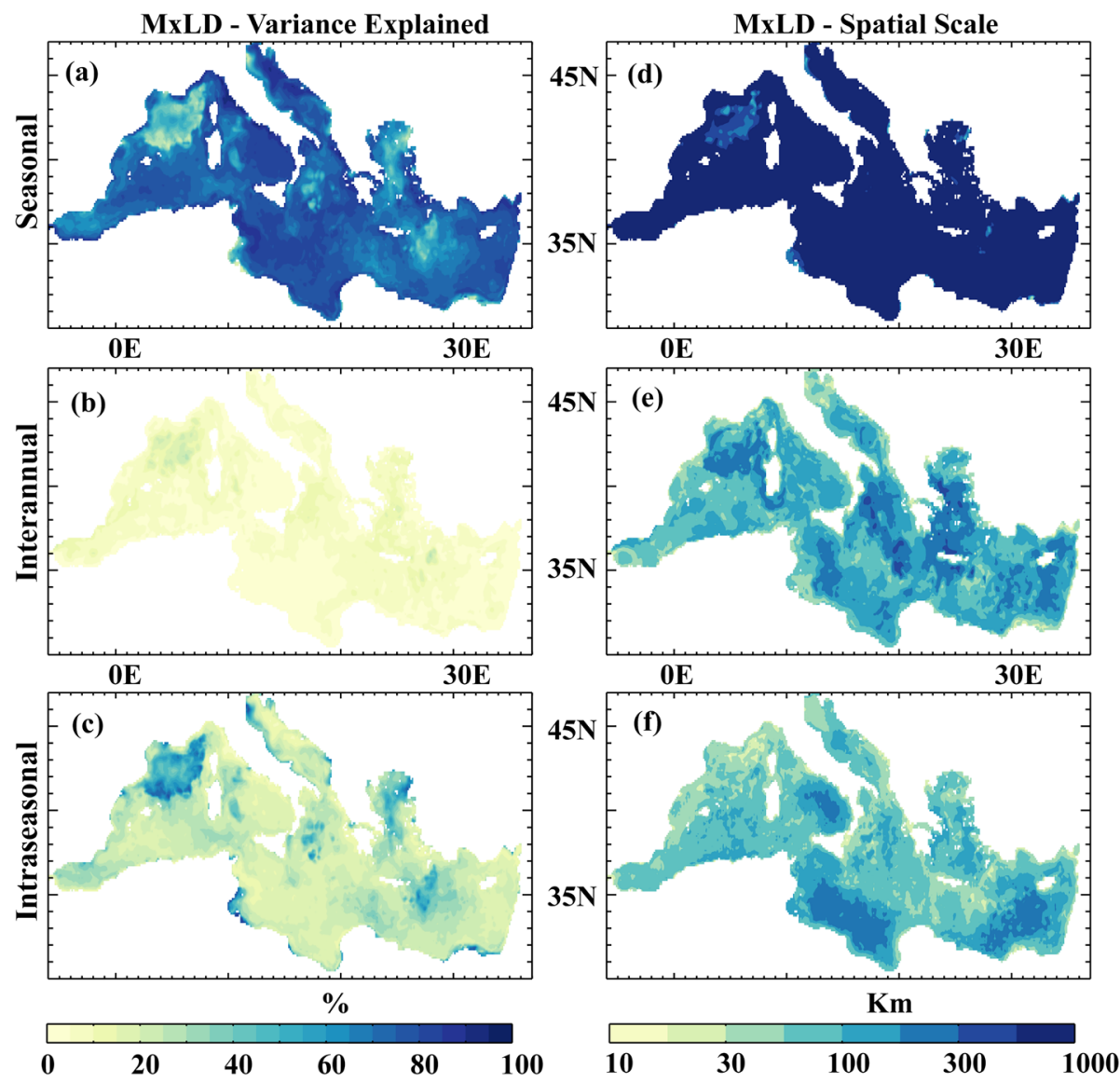

Figure 7. (first column) Percentage of the total mixing-layer depth (MxLD) variance explained by its (a) seasonal, (b) interannual, and (c) intraseasonal components. (second column) Spatial scales associated to (d) seasonal, (e) interannual, and (f) intraseasonal MxLD components.

which performs well in terms of large-scale patterns and captures some of the observed high-frequency variability, but could not be satisfactorily evaluated against in situ data for MxLD. It should also be noted that MxLD and SChl data are not analyzed over the same period, but restricting the SChl analysis over the period of overlap with the MxLD data does not affect the main results for SChl (see supporting information Figure S2).

The contribution of the seasonal, interannual, and intraseasonal variability to the total MxLD variance and the respective spatial scales involved are shown in Figure 7. Interestingly, the main patterns are similar for SChl and for MxLD: The seasonal signal dominates the total MxLD variations over most of the basin. It has the largest spatial scale, with a clear scale separation between the bloom region and the rest of the basin, highlighting two contrasted phenologies. Interannual variability is small in amplitude and has intermediate scales; Intraseasonal variability has an intermediate amplitude, which is maximum in the NW bloom region, and exhibits the smallest spatial scales of the three time scales of variability analyzed here.

There are however a few notable differences. First, there is a large interannual variability in MxLD in the deep convection zone of the NW bloom region, which reaches $\sim 20-30 \%$ of the total variability. This is consistent with previous studies, which highlighted strong year-to-year variations in the extent and timing of deep convection (Houpert et al., 2016; Mayot et al., 2016; Mertens \& Schott, 1998). This maximum in the interannual MxLD variance in the NW bloom region is not observed for SChl, confirming previous findings that interannual variations in the depth of convection do not drive substantial interannual variations of the bloom (Lavigne et al., 2013).

Second, in the no-bloom region, intraseasonal variations of the MxLD represent a larger part of its total variability than intraseasonal variations of the SChl. This suggests that intraseasonal variations of the 
MxLD remain generally too shallow to reach the nutricline there, as already suggested in the literature (Moutin \& Raimbault, 2002; Siokou-Frangou et al., 2010; Volpe et al., 2012). For example, along the Ionian and Levantine basin, the maximum winter MxLD is 82 and $125 \mathrm{~m}$, respectively, while the mean winter nitracline is located at around 100 and 145 m, respectively (de Fommervault et al., 2015).

In addition, the spatial scales associated with intraseasonal variations of the MxLD are notably larger than those associated with the intraseasonal variations of SChl in most of the basin (100-400 km for MxLD vs. 30-50 km for SChl), except in the NW bloom region where the opposite occurs (30-50 km for MxLD vs. 60-100 km for SChl) (Figures $5 \mathrm{f}$ and $7 \mathrm{f}$ ). This discrepancy in scales suggests that intraseasonal variability in SChl and MxLD might not be connected. We can also note that in the NW bloom region, the maximum intraseasonal variability in SChl and MxLD does not occur at the same time: It occurs in spring for SChl and in winter for MxLD (supporting information Figure S3).

This additional analysis confirms the important role of the MxLD in driving seasonal variations of SChl and also illustrates that interannual variability in SChl is not driven by interannual variability in MxLD. It has not allowed us to identify a connection between intraseasonal variability in SChl and intraseasonal variability in MxLD. This aspect is further discussed below.

\section{Summary and Discussion}

\subsection{Summary}

Our analysis based on two decades of merged ocean color data confirms previous findings regarding seasonal and interannual variability in SChl in the Mediterranean Sea, and brings new insight regarding intraseasonal SChl variability and its connection with seasonal and interannual fluctuations. As is the case in most ocean regions (Demarcq et al., 2012), seasonal fluctuations are the main contributor of SChl variability in the Mediterranean Sea (D'Ortenzio and d'Alcala, 2009; Salgado-Hernanz et al., 2019), and the physical processes driving this variability are reasonably well understood (Bosc et al., 2004; d'Ortenzio et al., 2014; d'Ortenzio \& Ribera d'Alcalà, 2009; Houpert et al., 2015; Houpert et al., 2016; Lavigne et al., 2013; Mayot et al., 2016). Our analysis on SChl seasonal variations are broadly consistent with these previous studies and put them in perspective with the spatio-temporal variability of the mixing layer. The spatial scales of SChl and MxLD at seasonal time scales (Figures 5d and 7d) are similar. They both reveal a bimodal spatial pattern, with a bloom region characterized by its own, relatively small spatial scale $(400 \mathrm{~km})$, embedded in a large "no-bloom" region $(>1000 \mathrm{~km})$. The boundary between the two regions is sharp and weakly sensitive to the threshold used to determine the spatial scale of correlation (supporting information Figures S4 and S5). It reflects that the seasonal cycle of SChl is well autocorrelated within each region, but poorly correlated from one region to the other. This is because the seasonal phasing of SChl differs in the bloom and no-bloom regimes, with a peak in spring in the bloom region driven by the shoaling of the MxLD after deep winter convection, and a peak in winter in the no-bloom regime driven by a moderate deepening of the MxLD (Lavigne et al., 2013). d'Ortenzio and Ribera d'Alcalà (2009) identified three different "no-bloom" regimes in the Mediterranean Sea and a wider transition between the bloom and no-bloom regions. Their results were based on a cluster analysis applied to a climatological time series constructed from ten years of satellite SChl data. These three no-bloom regions were organized along the east-west productivity gradient (their Figure 4) and reflected differences in amplitude rather than in the phenology.

While our analysis confirms that seasonal variations strongly dominate SChl variability in the oligotrophic "no-bloom" regime, which covers most of the Mediterranean Sea (e.g., Demarcq et al., 2012; d'Ortenzio \& Ribera d'Alcalà, 2009). It however reveals that intraseasonal SChl variability has similar amplitude to that of SChl seasonal variations in the "bloom" regime, which is confined to the northwest part of the basin. Interannual variations are everywhere weak in amplitude, as they represent between less than $10 \%$ to at most $20 \%$ of the total SChl variability (Figure 5), confirming the findings of previous studies (e.g., Basterretxea et al., 2018).

In the wide no-bloom region, the spatial scales of the small intraseasonal SChl variations are similar to those of oceanic mesoscale transport. This suggests that intraseasonal SChl fluctuations are due to intermittent nutrient supply driven by small-scale phenomena such as fronts and mesoscale eddies (Lévy et al., 2012; McGillicuddy and Dennis, 2016). Such intermittent supply is a common feature in oligotrophic regions 
(Doney et al., 2003), and its impact on SChl depends on the respective depth of the nutricline and of the vertical circulation associated with the small-scale dynamical features (Levy et al., 2018). We also note that intraseasonal SChl variations in the no-bloom region are not connected to intraseasonal variations of the MxLD, which have larger spatial scales. This is also consistent with the hypothesis that intraseasonal SChl variability is linked to mesoscale processes, and therefore to advective inputs of nutrients rather than detrainment or diffusive supplies.

In the most productive NW "bloom" regime, almost half of the SChl variations occur at intraseasonal time scales. Our results indicate that they are spatially coherent over a spatial scale $(\sim 100 \mathrm{~km})$ larger than the mesoscale $(\sim 20 \mathrm{~km})$ but smaller than the bloom area itself $(\sim 400 \mathrm{~km})$. A hypothesis to explain these strong SChl variations is that they could be related to variability in vertical mixing, driven by mechanical stress and buoyancy forcing associated with the passage of intermittent wind bursts. These events are frequent in this region (Mertens \& Schott, 1998; Leaman \& Schott, 1991; Bernadallo et al., 2012), and have spatial scales that are consistent with this hypothesis. However, with the MxLD product that we had, we could not identify any link between intraseasonal SChl and MxLD variations in the bloom region; In particular intraseasonal variations have larger spatial scales for SChl (60-100 km) than for MxLD (30-50 km). This difference is partially explained by the different time at which maximum intraseasonal variations occur, in winter for the MxLD and in spring for SChl (supporting information Figure S3). The large intraseasonal variability of the MxLD in winter is well established and is sustained by atmospheric forcing events that last for a few days (Houpert et al., 2016; Marshall \& Schott, 1999; Testor et al., 2018; Waldman et al., 2017). However, since $\mathrm{SChl}$ is very small in winter due to strong light limitation and dilution, its absolute variability in response to such forcing remains small. In contrast in spring, SChl is high and highly sensitive to small fluctuations of the MxLD. Modeling studies have suggested that the spatial scales of MxLD and SChl are both extremely variable during the bloom (Figures 8-10 in Lévy et al., 2005). Furthermore, as previously mentioned, we have not been able to properly evaluate the performance of the reanalysis in correctly reproducing the intraseasonal fluctuations of the MxLD during the bloom, which could therefore be of insufficient quality. This hinders our ability to connect MxLD and SChl intraseasonal variations statistically with the best data currently available. Dedicated investigation will be necessary to fully understand the physical processes driving intraseasonal fluctuations of SChl during the spring bloom. To this purpose, a modeling approach may prove to be very useful, as it would allow to overcome the scarcity of the data at the appropriate spatial and temporal scales.

Our analysis finally indicates that intraseasonal variability is not only a local phenomenon but can be felt over larger spatial scales. This influence of intraseasonal variations at spatial scales that are significantly larger than the autocorrelation length scale could possibly highlight scale interactions that are not fully understood, such as the remote and cumulative effect of mesoscale eddies and wind/eddy interactions (Lévy et al., 2014; Penduff et al., 2011).

Together, seasonal and intraseasonal variations account for most of the time variation, with less than $10 \%$ of the variability occurring at interannual time scales. This relatively small proportion of the SChl variance that is explained by the interannual ( $>1$ year) signal may seem surprising given the strong year-to-year variations that are evident in any individual SChl time series (e.g., Figure 2). This reflects that the variations that are seen in the timeseries are not interannual but are in fact intraseasonal, as confirmed by our analysis. These results are similar to those of Salgado-Hernanz et al. (2019) who employed a similar methodology with a different satellite merged product. The predominance of intraseasonal variability over interannual variability in the Mediterranean Sea is not specific to SChl and has also been reported for sea surface temperature (Zveryaev, 2015).

\subsection{Caveats}

The quantification of intraseasonal fluctuations of SChl in the ocean is impeded by two main difficulties. The first is the availability of data at the appropriate time scale, and the second is the method used to extract the intraseasonal signal. Regarding the first issue, we used a widely distributed ocean color product (OC-CCI), and assessed its skills at capturing the intraseasonal signal by comparing it to mooring data at the BOUSSOLE station. This comparison convinced us that the satellite product could be reliably used to study time variations, at least down to the resolution of the merged product, that is, 8 days. This conclusion holds for the Mediterranean basin where cloud cover is rather weak, but the use of satellite data could be more 
problematic in more cloudy regions. We should bear in mind, however, that the comparison implied a certain number of hypothesis, in particular the conversion of in situ fluorescence to chlorophyll using a constant ratio - a method previously validated by Lavigne et al. (2012), and the use of an ocean color algorithm that has been shown to overestimate low chlorophyll values in the Mediterranean Sea (Volpe et al., 2012). The quantification of the strength of intraseasonal SChl fluctuations in the Mediterranean Sea previously computed by Salgado-Hernanz et al. (2019) using a satellite product obtained from a regional algorithm (Med-OC4) was very similar to ours, highlighting that the small bias of OC-CCI compared to Med-OC4 only marginally affects our results.

The second issue lies in the definition of intraseasonal variability and on the methodology used to extract it from the total signal. This is especially critical for $\mathrm{SChl}$ as the strength of intraseasonal variability can reach that of seasonal variations. In order to extract the intraseasonal signal from seasonal and interannual fluctuations, we chose an approach that allows year-to-year variations of the seasonal cycle. This choice was dictated by the fact that the seasonal phenology of SChl differed between years (the number and the timing of the peaks). By construction, this method gives less weight to interannual fluctuations. Quantification of the respective weights with a second method where the seasonal cycle strictly repeats itself from year to year yields as expected slightly stronger interannual fluctuations and weaker seasonal and intraseasonal variations (supporting information Figure S6), but without impacting our main conclusions. The small differences are mostly due to variations at frequencies comprised between 3 and 6 months, which are not well subtracted from the interannual signal with the second method (Figure 3).

We should also note that variations in surface chlorophyll might not always reflect variations in depth-integrated biomass. In the Mediterranean Sea, the vertical distribution of chlorophyll is characterized by a subsurface maximum when conditions are oligotrophic, which is the case during summer in the bloom region and during most of the year in the no-bloom regions (i.e., Lavigne et al., 2012). This subsurface maximum is located near the depth of the nutricline, which is often well below the base of mixed layer (Cullen, 2015). As a consequence, the intraseasonal variability of this subsurface chlorophyll maximum may significantly differ from that of SChl both in amplitude and in phenology. In particular, we suspect this variability to be stronger than at the surface (Estrada, 1985; Latasa et al., 1992). Unfortunately, the lack of subsurface data at intraseasonal time scales precludes such an analysis.

\subsection{Concluding Remarks}

Acknowledgments

We acknowledge the support from CNES (Centre National d'Etudes Spatiales) and ANR SOBUMS (contract number : ANR-16-CE01-0014) for this Research. M. G. Keerthi is supported by a postdoctoral fellowship from CNES. The BOUSSOLE long-term time series project is supported by the European Space Agency (ESA Contract 4000119096/17/I-BG), the French Space Agency (CNES), the French National Center for Scientific Research (CNRS-INSU), and the Institut de la Mer de Villefranche (IMEV). The authors acknowledge BOUSSOLE observation group, Mercator reanalysis group, and European Space Agency Ocean Color Climate Change Initiative for providing the data used in this work. In situ BOUSSOLE data are available online (from http://www.obs-vlfr.fr/ Boussole/html/home/home.php), the Mercator reanalysis MEDRYS1V2 data are available on request (from https:// www.mercator-ocean.fr/), and the ESA OC-CCI SChl product is available online (at http://www.oceancolour.org/ ). Authors also acknowledge Dr. Jonathan Beuvier for providing the Mercator reanalysis data.
Overall, our study suggests that intraseasonal variability might represent a significant proportion of SChl variability over other bloom regions of the global ocean and that identifying and studying the processes that drive this variability are crucial to understand the variability of ocean productivity, including the long-term trends. Furthermore, more work is needed to transpose our results on SChl variability to variability in phytoplankton productivity, which is more relevant to ocean biogeochemical cycles than SChl (Behrenfeld, 2010; Boss \& Behrenfeld, 2010).

\section{References}

Antoine, D., Chami, M., Claustre, H., d'Ortenzio, F., Morel, A., Bécu, G., ... \& Scott, A. J. (2006). BOUSSOLE: A joint CNRS-INSU, ESA, CNES, and NASA ocean color calibration and validation activity. NASA Tech. Memo. TM-2006-214147, NASA GSFC, Greenbelt, MD, $59 \mathrm{pp}$.

Antoine, D., d'Ortenzio, F., Hooker, S. B., Bécu, G., Gentili, B., Tailliez, D., \& Scott, A. J. (2008). Assessment of uncertainty in the ocean reflectance determined by three satellite ocean color sensors (MERIS, SeaWiFS and MODIS-A) at an offshore site in the Mediterranean Sea (BOUSSOLE project). Journal of Geophysical Research: Oceans, 113(C7).

Basterretxea, G., Font-Muñoz, J. S., Salgado-Hernanz, P. M., Arrieta, J., \& Hernández-Carrasco, I. (2018). Patterns of chlorophyll interannual variability in Mediterranean biogeographical regions. Remote Sensing of Environment, 215, 7-17.

Behrenfeld, M. J. (2010). Abandoning Sverdrup's critical depth hypothesis on phytoplankton blooms. Ecology, 91(4), 977-989.

Behrenfeld, M. J., O'Malley, R. T., Siegel, D. A., McClain, C. R., Sarmiento, J. L., Feldman, G. C., et al. (2006). Climate-driven trends in contemporary ocean productivity. Nature, 444(7120), 752-755. https://doi.org/10.1038/nature05317

Bernardello, R., Cardoso, J. G., Bahamon, N., Donis, D., Marinov, I., \& Cruzado, A. (2012). Factors controlling interannual variability of vertical organic matter export and phytoplankton bloom dynamics-A numerical case-study for the NW Mediterranean Sea. Biogeosciences, 9(11), 4233-4245.

Bindoff, N.L., W.W.L. Cheung, J.G. Kairo, J. Arístegui, V.A. Guinder, R. Hallberg, et al., (2019). Changing ocean, marine ecosystems, and dependent communities. IPCC Special Report on the Ocean and Cryosphere in a Changing Climate [H.-O. Pörtner, D.C. Roberts, V. Masson-Delmotte, P. Zhai, M. Tignor, E. Poloczanska, K. Mintenbeck, A. Alegría, M. Nicolai, A. Okem, J. Petzold, B. Rama, N.M. Weyer (eds.)]. https://www.ipcc.ch/srocc/chapter/chapter-5/

Bosc, E., Bricaud, A., \& Antoine, D. (2004). Seasonal and interannual variability in algal biomass and primary production in the Mediterranean Sea, as derived from 4 years of SeaWiFS observations. Global Biogeochemical Cycles, 18(1). 
Boss, E., \& Behrenfeld, M. (2010). In situ evaluation of the initiation of the North Atlantic phytoplankton bloom. Geophysical Research Letters, 37(18).

Bosse, A., Testor, P., Mortier, L., Prieur, L., Taillandier, V., d'Ortenzio, F., \& Coppola, L. (2015). Spreading of Levantine intermediate waters by submesoscale coherent vortices in the northwestern Mediterranean Sea as observed with gliders. Journal of Geophysical Research: Oceans, 120(3), 1599-1622.

Brasseur, P., Bahurel, P., Bertino, L., Birol, F., Brankart, J. M., Ferry, N., et al. (2005). Data assimilation for marine monitoring and prediction: The MERCATOR operational assimilation systems and the MERSEA developments. Quarterly Journal of the Royal Meteorological Society: A journal of the atmospheric sciences, applied meteorology and physical oceanography, 131(613), 3561-3582.

Bricaud, A., Bosc, E., \& Antoine, D. (2002). Algal biomass and sea surface temperature in the Mediterranean Basin: Intercomparison of data from various satellite sensors, and implications for primary production estimates. Remote Sensing of Environment, 81(2-3), 163-178.

Carranza, M. M., \& Gille, S. T. (2015). Southern Ocean wind-driven entrainment enhances satellite chlorophyll-a through the summer. Journal of Geophysical Research: Oceans, 120(1), 304-323.

Chavez, F. P., Messié, M., \& Pennington, J. T. (2011). Marine primary production in relation to climate variability and change. Annual Review of Marine Science, 3, 227-260. https://doi.org/10.1146/annurev.marine.010908.163917

Colella, S., Falcini, F., Rinaldi, E., Sammartino, M., \& Santoleri, R. (2016). Mediterranean ocean colour chlorophyll trends. PLoS ONE, 11(6), e0155756. https://doi.org/10.1371/journal.pone.0155756

Cullen, J. J. (2015). Subsurface chlorophyll maximum layers: Enduring enigma or mystery solved? Annual Review of Marine Science, 7 , 207-239.

de Fommervault, O. P., d'Ortenzio, F., Mangin, A., Serra, R., Migon, C., Claustre, H., et al. (2015). Seasonal variability of nutrient concentrations in the Mediterranean Sea: Contribution of Bio-Argo floats. Journal of Geophysical Research: Oceans, 120(12), 8528-8550.

Demarcq, H., Reygondeau, G., Alvain, S., \& Vantrepotte, V. (2012). Monitoring marine phytoplankton seasonality from space. Remote Sensing of Environment, 117, 211-222.

Demirov, E., \& Pinardi, N. (2002). Simulation of the Mediterranean Sea circulation from 1979 to 1993: Part I. The interannual variability. Journal of Marine Systems, 33, 23-50.

Doney, S. C., Glover, D. M., McCue, S. J., \& Fuentes, M. (2003). Mesoscale variability of Sea-Viewing Wide Field-of-view Sensor (SeaWiFS) satellite ocean color: Global patterns and spatial scales. Journal of Geophysical Research: Oceans, 108(C2).

d'Ortenzio, F., Iudicone, D., de Boyer Montegut, C., Testor, P., Antoine, D., Marullo, S., et al. (2005). Seasonal variability of the mixed layer depth in the Mediterranean Sea as derived from in situ profiles. Geophysical Research Letters, 32(12).

d'Ortenzio, F., Lavigne, H., Besson, F., Claustre, H., Coppola, L., Garcia, N., et al. (2014). Observing mixed layer depth, nitrate and chlorophyll concentrations in the northwestern Mediterranean: A combined satellite and $\mathrm{NO}_{3}$ profiling floats experiment. Geophysical Research Letters, 41(18), 6443-6451.

d'Ortenzio, F., \& Prieur, L. (2012). The upper mixed layer. In N. Stambler (Ed.), Life in the Mediterranean Sea: A look at habitat changes, (pp. 127-156). Hauppage, N. Y: Nova Science Publishers.

d'Ortenzio, F., \& Ribera d'Alcalà, M. (2009). On the trophic regimes of the Mediterranean Sea: A satellite analysis. Biogeosciences, 6(2), 139-148.

Escudier, R., Renault, L., Pascual, A., Brasseur, P., Chelton, D., \& Beuvier, J. (2016). Eddy properties in the Western Mediterranean Sea from satellite altimetry and a numerical simulation. Journal of Geophysical Research: Oceans, 121(6), 3990-4006.

Estrada, M. (1985). Primary production at the deep chlorophyllmaximum in the western Mediterranean. In P. E. Gibbs (Ed.), Proceedings of the nineteenth European Marine Biology Sym-posium, (pp. 135-143). Cambridge: Cambridge University Press.

Estrada, M. (1996). Primary production in the northwestern Mediterranean. Scienta Marina, 60, 55-64.

Fauchereau, N., Tagliabue, A., Bopp, L., \& Monteiro, P. M. (2011). The response of phytoplankton biomass to transient mixing events in the Southern Ocean. Geophysical Research Letters, 38(17).

Fernández, V., Dietrich, D. E., Haney, R. L., \& Tintoré, J. (2005). Mesoscale, seasonal and interannual variability in the Mediterranean Sea using a numerical ocean model. Progress in Oceanography, 66(2-4), 321-340.

Gaertner, M. Á., González-Alemán, J. J., Romera, R., Domínguez, M., Gil, V., Sánchez, E., et al. (2016). Simulation of medicanes over the Mediterranean Sea in a regional climate model ensemble: Impact of ocean-atmosphere coupling and increased resolution. Climate Dynamics, 51(3), 1041-1057.

Gregg, W. W., \& Rousseaux, C. S. (2014). Decadal trends in global pelagic ocean chlorophyll: A new assessment integrating multiple satellites, in situ data, and models. Journal of Geophysical Research: Oceans, 119(9), 5921-5933.

Hamon, M., Beuvier, J., Somot, S., Lellouche, J. M., Greiner, E., Jordà, G., et al. (2016). Design and validation of MEDRYS, a Mediterranean Sea reanalysis over the period 1992-2013. Ocean Science, 12(2), 577-599.

Henderson, R. (1916). Note on graduation by adjusted average. Trans. Amer. Math.Soc., 1743-48.

Henson, S. A., Beaulieu, C., \& Lampitt, R. (2016). Observing climate change trends in ocean biogeochemistry: When and where. Global Change Biology, 22(4), 1561-1571. https://doi.org/10.1111/gcb.13152

Henson, S. A., Sarmiento, J. L., Dunne, J. P., Bopp, L., Lima, I., Doney, S. C., et al. (2010). Detection of anthropogenic climate change in satellite records of ocean chlorophyll and productivity. Biogeosciences, 7(2), 621-640.

Houpert, L., Durrieu de Madron, X., Testor, P., Bosse, A., d'Ortenzio, F., Bouin, M. N., et al. (2016). Observations of open-ocean deep convection in the northwestern Mediterranean Sea: Seasonal and interannual variability of mixing and deep water masses for the 2007-2013 period. Journal of Geophysical Research: Oceans, 121(11), 8139-8171.

Houpert, L., Testor, P., de Madron, X. D., Somot, S., D'ortenzio, F., Estournel, C., \& Lavigne, H. (2015). Seasonal cycle of the mixed layer, the seasonal thermocline and the upper-ocean heat storage rate in the Mediterranean Sea derived from observations. Progress in Oceanography, 132, 333-352.

Keerthi, M. G., Lengaigne, M., Drushka, K., Vialard, J., de Boyer Montégut, C., Pous, S., et al. (2016). Intraseasonal variability of mixed layer depth in the tropical Indian Ocean. Climate Dynamics, 46(7-8), 2633-2655.

Keerthi, M. G., Lengaigne, M., Lévy, M., Vialard, J., Parvathi, V., de Boyer Montégut, C., et al. (2017). Physical control of interannual variations of the winter chlorophyll bloom in the northern Arabian Sea. Biogeosciences, 14, 3615-3632.

Keerthi, M. G., Lengaigne, M., Vialard, J., de Boyer Montégut, C., \& Muraleedharan, P. M. (2013). Interannual variability of the tropical Indian Ocean mixed layer depth. Climate Dynamics, 40(3-4), 743-759.

Latasa, M., Estrada, M., \& Delgado, M. (1992). Plankton-pigment relationships in the northwestern Mediterranean during stratification. Marine Ecological Progress Series, 88, 61-73.

Lavigne, H., D'ortenzio, F., Claustre, H., \& Poteau, A. (2012). Towards a merged satellite and in situ fluorescence ocean chlorophyll product. Biogeosciences, 9(6), 2111-2125. 
Lavigne, H., D'ortenzio, F., d'Alcalà, M. R., Claustre, H., Sauzède, R., \& Gacic, M. (2015). On the vertical distribution of the chlorophyll a concentration in the Mediterranean Sea: A basin-scale and seasonal approach. Biogeosciences, 12, 5021-5039.

Lavigne, H., d'Ortenzio, F., Migon, C., Claustre, H., Testor, P., d'Alcalà, M. R., et al. (2013). Enhancing the comprehension of mixed layer depth control on the Mediterranean phytoplankton phenology. Journal of Geophysical Research: Oceans, 118(7), 3416-3430.

Lazzari, P., Solidoro, C., Ibello, V., Salon, S., Teruzzi, A., Béranger, K., et al. (2012). Seasonal and inter-annual variability of plankton chlorophyll and primary production in the Mediterranean Sea: A modelling approach. Biogeosciences, 9(1), $217-233$.

Leaman, K. D., \& Schott, F. A. (1991). Hydrographic structure of the convection regime in the Gulf of Lions: Winter 1987. Journal of Physical Oceanography, 21(4), 575-598.

Lévy, M., Ferrari, R., Franks, P. J., Martin, A. P., \& Rivière, P. (2012). Bringing physics to life at the submesoscale. Geophysical Research Letters, 39(14).

Lévy, M., Franks, P. J., \& Smith, K. S. (2018). The role of submesoscale currents in structuring marine ecosystems. Nature Communications, 9(1), 4758. https://doi.org/10.1038/s41467-018-07059-3

Lévy, M., Gavart, M., Mémery, L., Caniaux, G., \& Paci, A. (2005). A four-dimensional mesoscale map of the spring bloom in the northeast Atlantic (POMME experiment): Results of a prognostic model. Journal of Geophysical Research: Oceans, 110(C7).

Levy, M., Memery, L., \& Madec, G. (1998). The onset of a bloom after deep winter convection in the northwestern Mediterranean Sea: Mesoscale process study with a primitive equation model. Journal of Marine Systems, 16(1-2), 7-21.

Lévy, M., Mémery, L., \& Madec, G. (1999). The onset of the spring bloom in the MEDOC area: Mesoscale spatial variability. Deep Sea Research Part I: Oceanographic Research Papers, 46(7), 1137-1160.

Lévy, M., Resplandy, L., \& Lengaigne, M. (2014). Oceanic mesoscale turbulence drives large biogeochemical interannual variability at middle and high latitudes. Geophysical Research Letters, 41(7), 2467-2474.

Madec, G., Delecluse, P., Crépon, M., \& Lott, F. (1996). Large-scale preconditioning of deep-water formation in the northwestern Mediterranean Sea. Journal of Physical Oceanography, 26, 1393-1408.

Mahadevan, A., D'Asaro, E., Lee, C., \& Perry, M. J. (2012). Eddy-driven stratification initiates North Atlantic spring phytoplankton blooms. Science, 337(6090), 54-58. https://doi.org/10.1126/science.1218740

Marra, A. C., Federico, S., Montopoli, M., Avolio, E., Baldini, L., Casella, D., et al. (2019). The precipitation structure of the Mediterranean tropical-like Cyclone Numa: Analysis of GPM observations and numerical weather prediction model simulations. Remote Sens, 11, 1690.

Marshall, J., \& Schott, F. (1999). Open-ocean convection: Observations, theory, and models. Reviews of Geophysics, 37(1), 1-64.

Martinez, E., Antoine, D., D'Ortenzio, F., \& Gentili, B. (2009). Climate-driven basin-scale decadal oscillations of oceanic phytoplankton. Science, 326(5957), 1253-1256. https://doi.org/10.1126/science.1177012

Marty, J. C., \& Chiavérini, J. (2010). Hydrological changes in the Ligurian Sea (NW Mediterranean, DYFAMED site) during 1995-2007 and biogeochemical consequences. Biogeosciences, 7(7), 2117-2128.

Mayot, N., D'Ortenzio, F., d'Alcala, M. R., Lavigne, H., \& Claustre, H. (2016). Interannual variability of the Mediterranean trophic regimes from ocean color satellites. Biogeosciences, 13, 1901-1917.

Mayot, N., d'Ortenzio, F., Taillandier, V., Prieur, L., De Fommervault, O. P., Claustre, H., et al. (2017). Physical and biogeochemical controls of the phytoplankton blooms in north western Mediterranean Sea: A multiplatform approach over a complete annual cycle (20122013 DEWEX experiment). Journal of Geophysical Research: Oceans, 122(12), 9999-10,019.

McGillicuddy, D. J. Jr. (2016). Mechanisms of physical-biological-biogeochemical interaction at the oceanic mesoscale. Annual Review of Marine Science, 8, 125-159.

Menkès, C. E., Lengaigne, M., Lévy, M., Éthé, C., Bopp, L., Aumont, O., et al. (2016). Global impact of tropical cyclones on primary production. Global Biogeochemical Cycles, 30(5), 767-786.

Mertens, C., \& Schott, F. (1998). Interannual variability of deep-water formation in the northwestern Mediterranean. Journal of Physical Oceanography, 28(7), 1410-1424.

Migon C, Nival P, Sciandra A. (2020). The Mediterranean Sea in the era of global change-1: 30 years of multidisciplinary study of the Ligurian Sea. 1, ISTE Science Publishing LTD, Environmental Sciences Series, 9781786304285.

Mitchell, B. G., \& Holm-Hansen, O. (1991). Bio-optical properties of Antarctic Peninsula waters: Differentiation from temperate ocean models. Deep Sea Research Part A. Oceanographic Research Papers, 38(8-9), 1009-1028.

Molcard, A., Pinardi, N., Iskandarani, M., \& Haidvogel, D. B. (2002). Wind driven general circulation of the Mediterranean Sea simulated with a spectral Element Ocean model. Dynamics of Atmospheres and Oceans, 35(2), 97-130.

Moutin, T., \& Raimbault, P. (2002). Primary production, carbon export and nutrients availability in western and eastern Mediterranean Sea in early summer 1996 (MINOS cruise). Journal of Marine Systems, 33, 273-288.

Nieblas, A. E., Drushka, K., Reygondeau, G., Rossi, V., Demarcq, H., Dubroca, L., \& Bonhommeau, S. (2014). Defining Mediterranean and Black Sea biogeochemical subprovinces and synthetic ocean indicators using mesoscale oceanographic features. PLoS ONE, 9(10).

Olita, A., Ribotti, A., Sorgente, R., Fazioli, L., \& Perilli, A. (2011). SLA-chlorophyll-a variability and covariability in the Algero-Provençal Basin (1997-2007) through combined use of EOF and wavelet analysis of satellite data. Ocean Dynamics, 61, 89-102.

Pascual, A., Pujol, M. I., Larnicol, G., Le Traon, P. Y., \& Rio, M. H. (2007). Mesoscale mapping capabilities of multisatellite altimeter missions: First results with real data in the Mediterranean Sea. Journal of Marine Systems, 65(1-4), 190-211.

Pascual, A., Ruiz, S., Olita, A., Troupin, C., Claret, M., Casas, B., et al. (2017). A multiplatform experiment to unravel meso- and submesoscale processes in an intense front (AlborEx). Frontiers in Marine Science, 4, 39.

Penduff, T., Juza, M., Barnier, B., Zika, J., Dewar, W. K., Treguier, A.-M., et al. (2011). Sea level expression of intrinsic and forced ocean variabilities at interannual time scales. Journal of Climate, 24(21), 5652-5670.

Pinardi, N., Korres, G., Lascaratos, A., Roussenov, V., \& Stanev, E. (1997). Numerical simulation of the interannual variability of the Mediterranean Sea upper ocean circulation. Geophysical Research Letters, 24(4), 425-428.

Pinardi, N., \& Masetti, E. (2000). Variability of the large scale general circulation of the Mediterranean Sea from observations and modelling: A review. Palaeogeography, Palaeoclimatology, Palaeoecology, 158(3-4), 153-173.

Resplandy, L., Vialard, J., Lévy, M., Aumont, O., \& Dandonneau, Y. (2009). Seasonal and intraseasonal biogeochemical variability in the thermocline ridge of the southern tropical Indian Ocean. Journal of Geophysical Research: Oceans, 114(C7).

Robinson, A. R., Leslie, W. G., Theocharis, A., \& Lascaratos, A. (2001). Mediterranean Sea circulation. Ocean currents, $1,19$.

Ruiz, S., Claret, M., Pascual, A., Olita, A., Troupin, C., Capet, A., et al. (2019). Effects of oceanic mesoscale and submesoscale frontal processes on the vertical transport of phytoplankton. Journal of Geophysical Research: Oceans, 124(8), 5999-6014.

Salgado-Hernanz, P. M., Racault, M. F., Font-Muñoz, J. S., \& Basterretxea, G. (2019). Trends in phytoplankton phenology in the Mediterranean Sea based on ocean-colour remote sensing. Remote Sensing of Environment, 221, 50-64. 
Sathyendranath, S., Brewin, R. J., Jackson, T., Mélin, F., \& Platt, T. (2017). Ocean-colour products for climate-change studies: What are their ideal characteristics? Remote Sensing of Environment, 203, 125-138.

Sathyendranath. S., \& Krasemann, H. (2014). Ocean Colour Climate Change Initiative (OC-CCI)—Phase one. Climate Assessment Report. http://www.esa-oceancolour-cci.org/?q=documents.

Siokou-Frangou, I., Christaki, U., Mazzocchi, M. G., Montresor, M., Ribera d'Alcalá, M., Vaqué, D., \& Zingone, A. (2010). Plankton in the open Mediterranean Sea: A review. Biogeosciences, 7(5), 1543-1586.

Sverdrup, H. U. (1953). On conditions for the vernal blooming of phytoplankton. J. Cons. Int. Explor. Mer, 18(3), $287-295$.

Taylor, J. R., \& Ferrari, R. (2011). Shutdown of turbulent convection as a new criterion for the onset of spring phytoplankton blooms. Limnology and Oceanography, 56(6), 2293-2307.

Testor, P., Bosse, A., Houpert, L., Margirier, F., Mortier, L., Legoff, H., et al. (2018). Multiscale observations of deep convection in the northwestern Mediterranean Sea during winter 2012-2013 using multiple platforms. Journal of Geophysical Research: Oceans, 123(3), $1745-1776$.

Testor, P., Send, U., Gascard, J. C., Millot, C., Taupier-Letage, I., \& Béranger, K. (2005). The mean circulation of the southwestern Mediterranean Sea: Algerian gyres. Journal of Geophysical Research: Oceans, 110(C11).

Thomalla, S. J., Fauchereau, N., Swart, S., \& Monteiro, P. M. S. (2011). Regional scale characteristics of the seasonal cycle of chlorophyll in the Southern Ocean. Biogeosciences, 8(10), 2849-2866.

Vantrepotte, V., \& Mélin, F. (2009). Temporal variability of 10-year global SeaWiFS time-series of phytoplankton chlorophyll a concentration. ICES Journal of Marine Science, 66(7), 1547-1556.

Vantrepotte, V., \& Mélin, F. (2011). Inter-annual variations in the SeaWiFS global chlorophyll a concentration (1997-2007). Deep Sea Research Part I: Oceanographic Research Papers, 58(4), 429-441.

Volpe, G., Nardelli, B. B., Cipollini, P., Santoleri, R., \& Robinson, I. S. (2012). Seasonal to interannual phytoplankton response to physical processes in the Mediterranean Sea from satellite observations. Remote Sensing of Environment, 117, $223-235$.

Volpe, G., Santoleri, R., Vellucci, V., d'Alcalà, M. R., Marullo, S., \& d'Ortenzio, F. (2007). The colour of the Mediterranean Sea: Global versus regional bio-optical algorithms evaluation and implication for satellite chlorophyll estimates. Remote Sensing of Environment, 107(4), 625-638.

Waldman, R., Herrmann, M., Somot, S., Arsouze, T., Benshila, R., Bosse, A., et al. (2017). Impact of the mesoscale dynamics on ocean deep convection: The 2012-2013 case study in the northwestern Mediterranean Sea. Journal of Geophysical Research: Oceans, 122(11), $8813-8840$.

Weaver, A., \& Courtier, P. (2001). Correlation modelling on the sphere using a generalized diffusion equation. Quarterly Journal of the Royal Meteorological Society, 127(575), 1815-1846.

Zveryaev, I. I. (2015). Seasonal differences in intraseasonal and interannual variability of Mediterranean Sea surface temperature. Journal of Geophysical Research: Oceans, 120(4), 2813-2825. 